\title{
Correlation between PPAR- $\alpha$ methylation level in peripheral blood and atherosclerosis of NAFLD patients with DM
}

\author{
JIANGHUA JU, QINGXIAN HUANG, JING SUN, XIAOYUN ZHAO, XIULI GUO, \\ YONGCHENG JIN, WENJIE MA and WENHUI WANG \\ Department of Endocrinology, Qilu Hospital of Shandong University, \\ Qingdao, Shandong 266035, P.R. China
}

Received June 20, 2017; Accepted October 5, 2017

DOI: $10.3892 /$ etm.2018.5730

\begin{abstract}
We investigated the correlation between the methylation levels of peroxisome proliferator-activated receptor- $\alpha$ (PPAR- $\alpha$ ) in the peripheral blood and atherosclerosis in patients with nonalcoholic fatty liver disease (NAFLD) with diabetes mellitus (DM). A total of 50 normal subjects (group N) and 50 NAFLD patients with DM (group M) were selected at Qilu Hospital of Shandong University. The levels of total cholesterol (TC), triglyceride (TG), high-density lipoprotein (HDL) and low-density lipoprotein (LDL) in groups $\mathrm{N}$ and $\mathrm{M}$ were detected. The mRNA and protein expressions of PPAR- $\alpha$ in groups $\mathrm{N}$ and $\mathrm{M}$ were detected using reverse transcription polymerase chain reaction (PCR) and immunofluorescence. The differences in expression of PPAR- $\alpha$ in group $\mathrm{N}$ and $\mathrm{M}$ and the correlation between PPAR- $\alpha$ methylation level and atherosclerosis were analyzed using SPSS17.0 statistical software. TC, TG, HDL and LDL in groups $\mathrm{N}$ and $\mathrm{M}$ were significantly different $(\mathrm{P}<0.01)$. Hematoxylin and eosin staining showed that the histopathological damage was severe in group M. PCR and immunofluorescence showed that PPAR- $\alpha$ was significantly higher in $\mathrm{N}$ than in group $\mathrm{M}(\mathrm{P}<0.01)$. The abnormal expression of PPAR- $\alpha$ is closely related to atherosclerosis, indicating that the correlation between PPAR- $\alpha$ methylation levels in peripheral blood and atherosclerosis of NAFLD patients with DM can provide a new direction of diagnosis and treatment.
\end{abstract}

\section{Introduction}

Nonalcoholic fatty liver disease (NAFLD) refers to a type of complex disease with excessive fat accumulation in

Correspondence to: Dr Wenhui Wang, Department of Endocrinology, Qilu Hospital of Shandong University, 758 Hefei Road, Shibei, Qingdao, Shandong 266035, P.R. China E-mail: wangwenhuiqd@163.com

Key words: PPAR- $\alpha$, nonalcoholic fatty liver disease, diabetes mellitus, atherosclerosis hepatocytes that are the results of a variety of external and internal causes (1). Diabetes mellitus (DM) is closely related to NAFLD and can seriously threatens people's health. The number of NAFLD patients with DM is increasing yearly, however, its molecular mechanism of pathogenesis remains unclear. NAFLD complicated with DM has been considered a global health problem (2-4). Atherosclerosis manifests due to abnormal blood lipid metabolism, and current studies show that it is closely related to NAFLD complicated with DM (5). Previous studies have found that a subtype of peroxisome proliferator activated receptors (PPARs), peroxisome proliferator-activated receptor- $\alpha$ (PPAR- $\alpha$ ), have the effect of regulating glucose and lipid metabolism, thus participating in the occurrence and regulation of hyperglycemia and hyperlipidemia (6). A large number of previous studies have shown that DNA methylation plays an important role in metabolic diseases (7). There have been no report on whether PPAR- $\alpha$ methylation plays a role in the pathogenesis of atherosclerosis. In this study, NAFLD patients with DM were used as subjects to determine the relationship between PPAR- $\alpha$ methylation levels and atherosclerosis, providing a theoretical and experimental basis for clarifying the pathogenesis of NAFLD complicated with DM and finding new targets for the treatment of atherosclerosis.

\section{Materials and methods}

Sample selection. Patients that received physical examination at Qilu Hospital of Shandong University from May 2002 to April 2016 were enrolled as the subjects of study, and their blood samples were obtained. Subjects were divided into either the healthy control group (group $\mathrm{N}, \mathrm{n}=50$ ), including 28 males and 22 females aged between 32-51 years, or the NAFLD complicated with DM group (group M, n=50), including 30 males and 20 females aged 38-62 years. All subjects had complete clinical data. The study was approved by the Ethics Committee of Qilu Hospital of Shandong University and informed consents were signed by the patients and/or guardians.

Main reagents. The total cholesterol (TC), triglyceride (TG), high-density lipoprotein (HDL) and low-density lipoprotein 
(LDL) detection kits were obtained from Nanjing Jiancheng Bio-Engineering Institute Co., Ltd. (Nanjing, China). The TRIzol total RNA extraction kit and the polymerase chain reaction (PCR) reverse transcription kit was obtained from Tiangen Biotech Co., Ltd. (Beijing, China). The mouse anti-human PPAR- $\alpha$ monoclonal antibody (dilution, 1:300; cat. no. sc-130640) and bovine anti-mouse IgG-HRP secondary polyclonal antibody (dilution, 1:1,000; cat. no. sc-2371) was obtained from Santa Cruz Biotechnology (Philadelphia, PA, USA).

General data collection. The general information of the subjects, including sex, age, height, weight, past histories of drinking and hyperlipidemia, and a history of DM, hypertension and other disorders were collected using medical records combined with a questionnaire survey. The levels of TC, TG, HDL, LDL and liver functions were detected.

Determination of biochemical indexes. A total of $3 \mathrm{ml}$ of fasting peripheral venous blood were drawn in the early morning, placed in a coagulation-promoting tube, and centrifuged for $6 \mathrm{~min}$ at 2,680 $\mathrm{x}$ g after natural solidification. TC, TG, HDL, LDL and other indexes of the subjects were detected.

Extraction of DNA in blood cells. The fasting whole blood was drawn in the early morning from the patients, and the anticoagulant tube was used to avoid hemolysis. After being placed at room temperature for $1 \mathrm{~h}$, the whole blood samples were transferred to the polypropylene EP tube. All samples were uniformly encoded and stored in a cryogenic refrigerator at $-80^{\circ} \mathrm{C}$. The blood cell sample library was built for the PCR detection of PPAR- $\alpha$.

$P C R$. A PCR instrument was used to amplify the target gene's forward primer 5'-AGTAGGGGCGGGTATGGTTTTTG-3', and reverse primer 5'-ACCTCCTCAATAAACCCAACTCT ACTACTC-3', and the target fragment size was $133 \mathrm{bp}$. Amplification conditions were as follows: Preheating at $94^{\circ} \mathrm{C}$ for $5 \mathrm{~min}, 94^{\circ} \mathrm{C}, 58^{\circ} \mathrm{C}$ and $72^{\circ} \mathrm{C}$ for $30 \mathrm{sec}$, a total of 40 cycles, and extension at $72^{\circ} \mathrm{C}$ for $10 \mathrm{~min}$. The optical density ratio of PPAR- $\alpha$ to the corresponding internal control, $\beta$-actin, was detected using an agarose gel electrophoresis, and the relative content of PCR products was determined.

Immunofluorescent staining. After hepatic tissues in $\mathrm{N}$ and $\mathrm{M}$ groups were fixed with $10 \%$ formaldehyde for $48 \mathrm{~h}$, they were embedded into paraffin and prepared into $5 \mu \mathrm{m}$-thick section slides. Paraffin sections were dewaxed with xylene, dehydrated with alcohol at a gradient concentration and repaired with antigens. Then, the sections were rinsed with $0.01 \mathrm{M}$ polybutylene succinate (PBS) ( $\mathrm{pH} 7.4) 3$ times ( $5 \mathrm{~min} / \mathrm{time})$. Then, the sections were stored in a $10 \%$ BSA wet box for $30 \mathrm{~min}$ at $37^{\circ} \mathrm{C}$. The appropriately diluted (1:70) fluorescence-labeled antibodies was dropped onto the sections and placed in a wet box for incubation overnight at $4^{\circ} \mathrm{C}$. After being washed with PBS 3 times ( $5 \mathrm{~min} /$ time), the fluorescence secondary antibodies (diluted at 1:100) were dropped and incubated for $2 \mathrm{~h}$ in a wet box at $37^{\circ} \mathrm{C}$. Finally, sections were sealed using buffered glycerinum, followed by observation under the fluorescent microscope (Olympus, Tokyo, Japan).
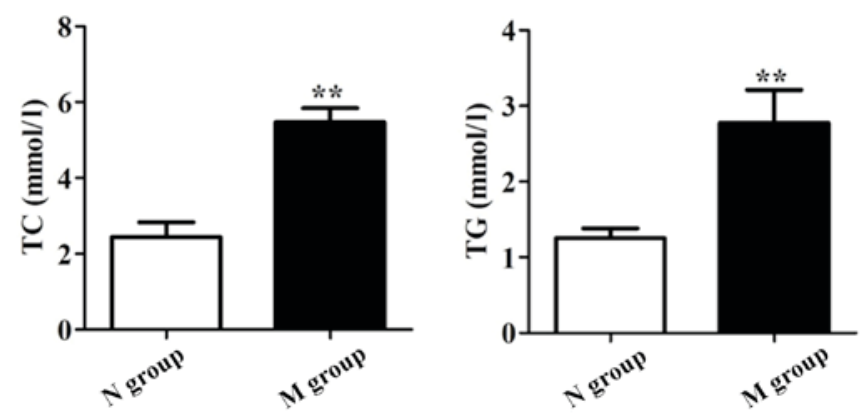

Figure 1. Expression of TC and TG in groups $\mathrm{N}$ and $\mathrm{M}$. Compared with group $\mathrm{N},{ }^{* *} \mathrm{P}<0.01$.
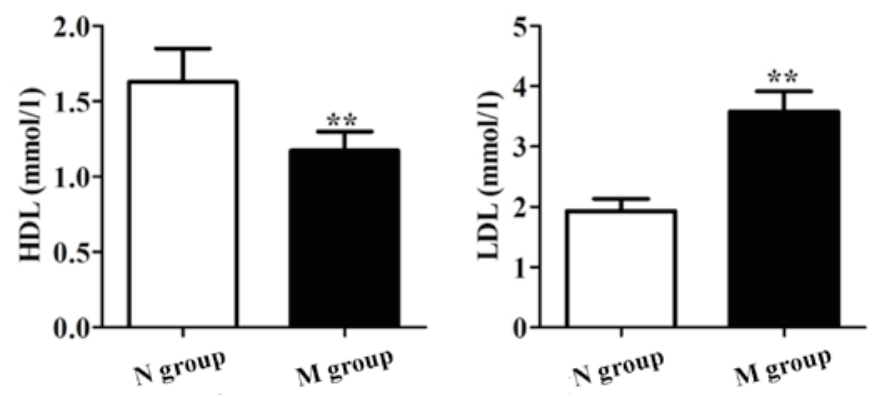

Figure 2. Expression of HDL and LDL in groups $\mathrm{N}$ and $\mathrm{M}$. Compared with group $\mathrm{N},{ }^{* *} \mathrm{P}<0.01$.

Statistical analysis. The experimental data were presented as mean \pm standard deviation (mean $\pm \mathrm{SD}$ ). The experimental results were analyzed using SPSS 17.0 (SPSS, Inc., Chicago, IL, USA) statistical software. The means between both groups were compared using the t-test. The mean among the groups were compared using a one-way analysis of variance (ANOVA). The $\mathrm{p}$-test was used for pairwise comparison. $\mathrm{P}<0.05$ was considered to indicate statistically significant differences.

\section{Results}

Comparison of subjects. The height and body weight of group $\mathrm{M}$ were on average $162.00 \pm 6.12$ and $64.21 \pm 7.31$, respectively. Subjects in group $\mathrm{N}$ had a height and body weight of $165.22 \pm 8.21$ and $62.97 \pm 9.21$, respectively. Differences between the two groups were not statistically significant $(\mathrm{P}>0.05)$. BMI in group $\mathrm{M}$ was $24.69 \pm 2.93$, which was significantly higher than that in group $\mathrm{N}(23.31 \pm 2.14)(\mathrm{P}<0.05)$.

Biochemical indexes. As shown in Figs. 1 and 2, TC, TG, HDL and LDL were significantly different between groups $\mathrm{N}$ and $\mathrm{M}$ $(\mathrm{P}<0.05)$. Our results showed that patients in group $\mathrm{M}$ suffered from dyslipidemia, and NAFLD patients with DM suffered from atherosclerosis compared to group $\mathrm{N}$.

Observation of pathological situation via $H \& E$ staining. Hematoxylin and eosin (H\&E) stained sections of normal liver tissues and liver tissues of NAFLD patients with DM were used to determine the pathological differences between each sample. Compared to normal liver tissue sections, substantial fatty degeneration occurred, lipid droplets were visible 


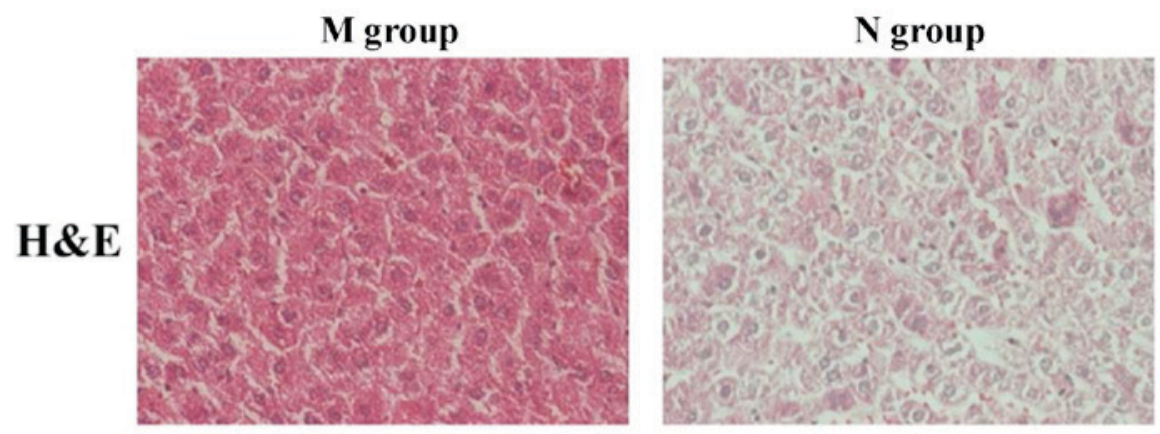

Figure 3. H\&E staining results of liver tissues in groups $\mathrm{N}$ and $\mathrm{M}(\mathrm{x} 400)$. H\&E, hematoxylin and eosin.

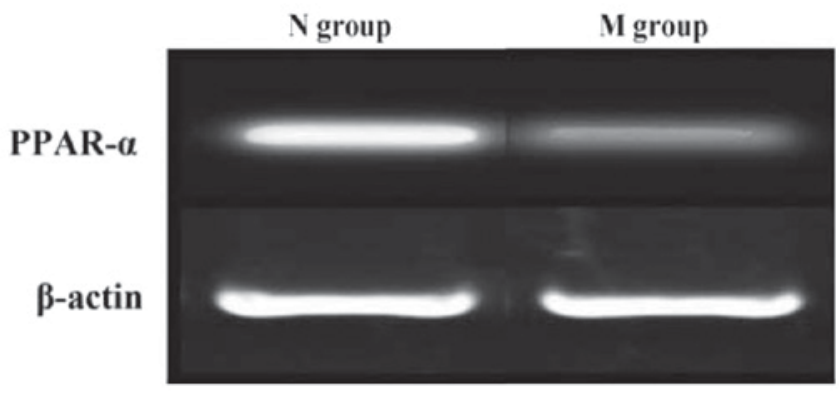

Figure 4. Expression of PPAR- $\alpha$ mRNA in groups $N$ and M. PPAR- $\alpha$ peroxisome proliferator-activated receptor- $\alpha$.
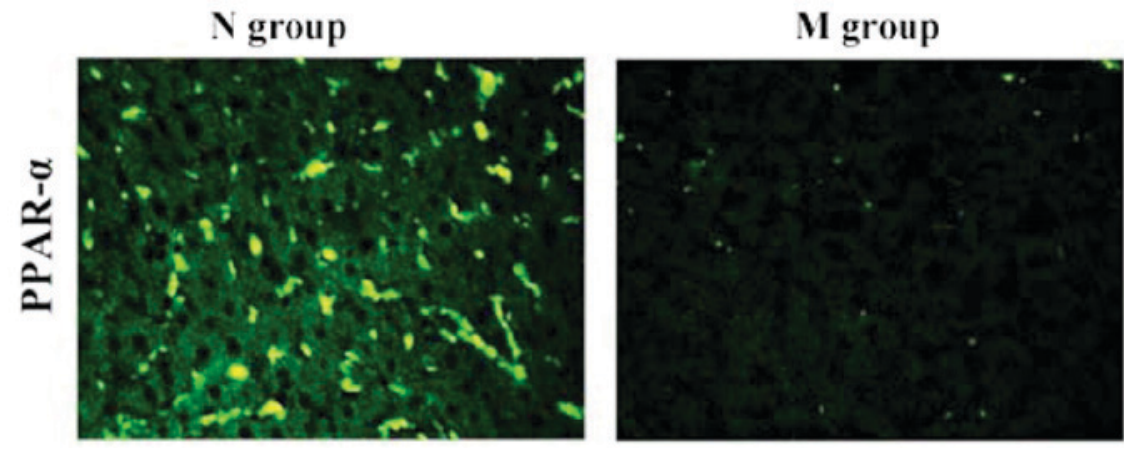

Figure 5. Immunofluorescence staining results of PPAR- $\alpha$ protein in groups $\mathrm{N}$ and M (magnification, $\mathrm{x} 400$ ). PPAR- $\alpha$ peroxisome proliferator-activated receptor- $\alpha$.

in the liver, liver tissue structures were changed and a large number of hepatocytes had swelling and injury in group $\mathrm{M}$. As shown in Fig. 3, there was a significant difference in the histopathology between normal liver tissues and liver tissues of NAFLD patients with DM.

Reverse transcription-polymerase chain reaction results. RNA was extracted from normal liver tissues and liver tissues of NAFLD patients with DM. PCR amplification showed that the expression of PPAR- $\alpha$ in normal liver tissue was significantly higher than that in liver tissues of NAFLD patients with DM (Fig. 4).

Immunofluorescence staining results. As shown in Fig. 5, PPAR- $\alpha$ was highly expressed in normal liver tissues, but rarely expressed in liver tissues of NAFLD patients with DM. Our results suggested that PPAR- $\alpha$ plays an important role in the development and progression of atherosclerosis induced by NAFLD complicated with DM.

\section{Discussion}

Improvement in living standards in previous years have led to changes in the dietary structure and lifestyle. Currently, the incidence rate of NAFLD and DM have also shown a significantly rising trend $(8,9)$. NAFLD complicated with DM is a complex disease that affects fat metabolism and glucose metabolism due to a variety of factors, including external and internal causes (10). It may gradually develop into more serious diseases or even threaten life and health if left untreated. Therefore, research on prevention and treatment of NAFLD complicated with DM has increasingly become a research hotspot and focus for all of society and the medical community. NAFLD patients with DM suffer from 
hyperglycemia, hyperlipidemia, high cholesterol, insulin resistance and other pathological symptoms (11). In the long term, the cardiovascular system may suffer, and NAFLD complicated with DM is closely related to the occurrence of atherosclerosis (12). However, the therapeutic approach of NAFLD complicated with DM remains to be studied, and the molecular mechanism of its pathogenesis is also unclear. Therefore, more studies are needed to explore this field.

PPAR is a class of transcription factors that are activated by a ligand, which belong to the nuclear receptor superfamily (13). There are three subtypes of PPARs that are encoded by different genes, with differing structures and functions. PPAR- $\alpha$ mainly exists in the fat, liver, heart, kidney, stomach and duodenal mucosa. It is also highly expressed in the pancreas islet (14). Previous findings have shown that PPAR- $\alpha$ binds to a ligand and plays a role in a variety of biological effects. PPAR- $\alpha$ has the effect of regulating glucose-lipid metabolism, inflammation, immunity and cell differentiation. PPAR- $\alpha$-mediated fatty acid oxidation and fat metabolism are particularly important (15). PPAR- $\alpha$ target gene is related to lipid transport and metabolic pathways, which can adjust the expression of fat absorption and metabolism-related genes with a close relationship with the occurrence and development of a variety of metabolic diseases (16). PPAR- $\alpha$ is involved in lipid metabolism and regulation of inflammation and cell differentiation through a variety of mechanisms. In this manner, PPAR- $\alpha$ may play an important regulatory role in the pathogenesis of NAFLD complicated with DM.

DNA methylation is one of the most characteristic markers of epigenetics, as well as the most in-depth mechanism of epigenetic research (17). The active methyl is transferred to the C5 of the cytosine by catalysis of DNA methyltransferase to form methylcystein. Therefore, methylation is generally associated with gene silencing, whereas demethylation can often re-activate silencing genes $(18,19)$. Previous findings have shown that DNA methylation is important in metabolic diseases. Based on the findings, our results suggest that methylation of PPAR- $\alpha$ plays an important role in the occurrence and development of NAFLD complicated with DM (20). In the present study, the levels of TC, TG, HDL and LDL in the diseases and control populations were determined, and PCR and immunofluorescence were used to detect PPAR- $\alpha$ expression in both groups. The role of PPAR- $\alpha$ methylation in the pathogenesis of NAFLD complicated with DM and its correlation with atherosclerosis were clarified, providing theoretical support for targeted therapy of NAFLD complicated with DM.

\section{Competing interests}

The authors declare that they have no competing interests.

\section{References}

1. Vernon G, Baranova A and Younossi ZM: Systematic review: The epidemiology and natural history of non-alcoholic fatty liver disease and non-alcoholic steatohepatitis in adults. Aliment Pharmacol Ther 34: 274-285, 2011.

2. Charlton M: Nonalcoholic fatty liver disease: A review of current understanding and future impact. Clin Gastroenterol Hepatol 2: 1048-1058, 2004.
3. Lazo M, Hernaez R, Bonekamp S, Kamel IR, Brancati FL, Guallar E and Clark JM: Non-alcoholic fatty liver disease and mortality among US adults: Prospective cohort study. BMJ 343: d6891, 2011.

4. Nestel PJ and Mensink RP: Perspective: Nonalcoholic fatty liver disease and cardiovascular risk. Curr Opin Lipidol 24: 1-3, 2013

5. Bhatia LS, Curzen NP, Calder PC and Byrne CD: Non-alcoholic fatty liver disease: A new and important cardiovascular risk factor. Eur Heart J 33: 1190-1200, 2012

6. Barger PM and Kelly DP: PPAR signaling in the control of cardiac energy metabolism. Trends Cardiovasc Med 10: 238-245, 2000.

7. Lee SST, Pineau T, Drago J, Lee EJ, Owens JW, Kroetz DL, Fernandez-Salguero PM, Westphal H and Gonzalez FJ: Targeted disruption of the $\alpha$ is oform of the peroxisome proliferator-activated receptor gene in mice results in abolishment of the pleiotropic effects of peroxisome proliferators. Mol Cell Biol 15: 3012-3022, 1995

8. Targher G, Day CP and Bonora E: Risk of cardiovascular disease in patients with nonalcoholic fatty liver disease. $\mathrm{N}$ Engl J Med 363: 1341-1350, 2010.

9. Pacana T and Fuchs M: The cardiovascular link to nonalcoholic fatty liver disease: A critical analysis. Clin Liver Dis 16: 599-613, 2012.

10. Lu H, Liu H, Hu F, Zou L, Luo S and Sun L: Independent association between nonalcoholic fatty liver disease and cardiovascular disease: A systematic review and meta-analysis. Int J Endocrinol 2013: 124958, 2013.

11. Villanova N, Moscatiello S, Ramilli S, Bugianesi E, Magalotti D, Vanni E, Zoli M and Marchesini G: Endothelial dysfunction and cardiovascular risk profile in nonalcoholic fatty liver disease. Hepatology 42: 473-480, 2005.

12. Akabame S, Hamaguchi M, Tomiyasu K, Tanaka M, Kobayashi-Takenaka Y, Nakano K, Oda Y and Yoshikawa T: Evaluation of vulnerable coronary plaques and non-alcoholic fatty liver disease (NAFLD) by 64-detector multislice computed tomography (MSCT). Circ J 72: 618-625, 2008

13. Djouadi F, Weinheimer CJ, Saffitz JE, Pitchford C, Bastin J, Gonzalez FJ and Kelly DP: A gender-related defect in lipid metabolism and glucose homeostasis in peroxisome proliferatoractivated receptor $\alpha$ - deficient mice. J Clin Invest 102: 1083-1091, 1998.

14. Aoyama T, Peters JM, Iritani N, Nakajima T, Furihata K, Hashimoto T and Gonzalez FJ: Altered constitutive expression of fatty acid-metabolizing enzymes in mice lacking the peroxisome proliferator-activated receptor $\alpha$ (PPARalpha). J Biol Chem 273: 5678-5684, 1998.

15. Leone TC, Weinheimer CJ and Kelly DP: A critical role for the peroxisome proliferator-activated receptor alpha (PPARalpha) in the cellular fasting response: The PPARalpha-null mouse as a model of fatty acid oxidation disorders. Proc Natl Acad Sci USA 96: 7473-7478, 1999.

16. Kersten S, Seydoux J, Peters JM, Gonzalez FJ, Desvergne B and Wahli W: Peroxisome proliferator-activated receptor $\alpha$ mediates the adaptive response to fasting. J Clin Invest 103: 1489-1498, 1999.

17. Moore LD, Le T and Fan G: DNA methylation and its basic function. Neuropsychopharmacology 38: 23-38, 2013.

18. Niculescu MD and Zeisel SH: Diet, methyl donors and DNA methylation: Interactions between dietary folate, methionine and choline. J Nutr 132: 2333-2335, 2002.

19. Oakes CC, La Salle S, Robaire B and Trasler JM: Evaluation of a quantitative DNA methylation analysis technique using methylation-sensitive/dependent restriction enzymes and real-time PCR. Epigenetics 1: 146-152, 2006.

20. Contreras AV, Torres $N$ and Tovar AR: PPAR- $\alpha$ as a key nutritional and environmental sensor for metabolic adaptation. Adv Nutr 4: 439-452, 2013. International (CC BY-NC-ND 4.0) License. 